\title{
Mechanisms of Action and Efficacy of Statins against Influenza
}

\author{
Parvaneh Mehrbod,, ${ }^{1,2}$ Abdul Rahman Omar, ${ }^{1,2}$ Mohd Hair-Bejo, ${ }^{1,2}$ \\ Amin Haghani, ${ }^{1}$ and Aini Ideris ${ }^{1,2}$ \\ ${ }^{1}$ Institute of Bioscience, Universiti Putra Malaysia, 43400 Serdang, Selangor, Malaysia \\ ${ }^{2}$ Faculty of Veterinary Medicine, Universiti Putra Malaysia, 43400 Serdang, Selangor, Malaysia \\ Correspondence should be addressed to Aini Ideris; aiini@upm.my
}

Received 6 June 2014; Revised 8 September 2014; Accepted 10 September 2014; Published 11 November 2014

Academic Editor: Kelvin To

Copyright (C) 2014 Parvaneh Mehrbod et al. This is an open access article distributed under the Creative Commons Attribution License, which permits unrestricted use, distribution, and reproduction in any medium, provided the original work is properly cited.

\begin{abstract}
The influenza virus (IV) is known to be a resistant virus with frequent mutations, causing severe respiratory diseases in the upper respiratory system. Public health concerns about clinical efficacy of all conventional drugs are ambiguous; therefore, finding additional therapeutic agents is critical to prevent and control influenza outbreaks. Influenza is associated with the induction of proinflammatory cytokines. Scientists have reported that anti-inflammatory drugs, with pleiotropic effects, reduce the burden of severe influenza diseases. Therefore, statins, which are cardioprotective drugs with anti-inflammatory and immunomodulatory effects, may help patients suffering from influenza virus (IV). This review delineates the potential use of statins as an alternative therapy in treating influenza related illness.
\end{abstract}

\section{Statins}

Statins are hydroxyl methylglutaryl-coenzyme A (HMGCoA) reductase enzyme inhibitors. This enzyme is responsible for the rate determining in early step of cholesterol biosynthesis pathway [1], which catalyses the reduction of HMGCoA to mevalonate during the synthesis of cholesterol [2]. Statins are pleiotropic cardioprotective drugs, increasingly recognized as mediators of direct cellular effects beyond their lipid lowering capacity [3]. Statins can block downstream molecules which are key factors in virus infectivity [4]. They reduce or block the synthesis of downstream isoprenoid intermediates, such as farnesyl pyrophosphate (FPP) and geranylgeranyl pyrophosphate (GGPP) [5]. These isoprenoid intermediates are lipid attachments for the posttranslational modification of proteins that interact with membranes. Statins manage their GTP- and GDP-bound state by controlling their isoprenylation and inhibiting the movement of their inactive form from cytosol to the membrane [6].

Therefore, statins that decrease the synthesis of isoprenoid intermediates, inhibit their membrane translocation and activity $[6,7]$. Pleiotropic effects of statins are thought to be mediated by reduction in the isoprenylation of many proteins. This can be illustrated by the Rho GTPase family: RhoA, Rac, and Cdc42 that serves specific functions in terms of cell shape, motility, secretion, proliferation, and regulation of gene expression [6]; Ras family also requires an attachment of a farnesyl group for their actions and membrane associations to play a role in cellular differentiation and proliferation [8]; Rab family, which are necessary for vesicle transportation inside the cell [8]; and Rap family, which are known to play a role in cell replication, oxygen radicals generation and platelet activation [7]. The diagram shows the pathways of statin effects on cellular and molecular structures that may interfere with influenza pathogenesis.

A considerable amount of literature has discussed pleiotropic effects of statins on leukocyte-endothelial interaction, intra- and intercellular signaling, inflammatory gene transcription, hemoxygenase expression, and expression of MHC class II antigens [9, 10]. In addition, anti-inflammatory and immunomodulatory properties have been shown by many other studies $[9,11-14]$.

Thus, statin drugs have captivated attention to have clinical significance in the preventative treatment averse to cellular damage caused by infectious agents $[15,16]$. Furthermore, statins can reduce sepsis and infections associated with 
complex inflammatory reactions, which is by virtue of the diverse and extrabeneficial anti-inflammatory effects that are independent of their lipid-lowering ability [17].

\section{Influenza Virus (IV)}

Influenza A virus is the causative agent for respiratory infections. Since 2009, a new reassorted A/H1N1 virus had circulated worldwide among humans, causing morbidity and mortality, and was referred to as a pandemic H1N1 (pH1N1) $[18,19]$. The clinical manifestations and the severity of illnesses following influenza infections are the result of immune dysregulations. This can be exemplified by release of proinflammatory cytokines that cause severe complications like hypercytokinemia $[20,21]$. This condition can be terminal in some strains like H5N1 [22, 23] and H1N1 [24].

The currently-approved classes of antiviral drugs for the treatment of influenza viral infections include neuraminidase inhibitors (zanamivir and oseltamivir) and M2 channel blockers (amantadine and rimantadine) [35]. Resistance to both classes is a steady dilemma. A widespread resistance to the only orally bioavailable neuraminidase inhibitor, oseltamivir, was encountered in the 2008-2009 [36] and 2009-2010 influenza seasons [37]. Although amantadine was successfully used for more than three decades, widespread resistance against this compound has made the Center for Disease Control and Prevention (CDC) in the US to advise against continuing usage of this drug [38]. Due to the fact that the next occurrence of influenza epidemic or pandemic is unpredictable, it is required to have an effective treatment strategy.

However, no new classes of medications have convincingly demonstrated the characteristics to ameliorate the clinical outcomes of influenza infection. Therefore, there is an imperative need for the development of anti-influenza drugs with broad reactivity against all strains and subtypes. Hence, it is necessary to contemplate the option of moving into multiple drug therapy. Moreover, finding effective alternative therapy to reduce the complications of influenza is required $[16,39]$. In this respect, other effective and safe drugs, which bypass the possibility of developing resistance, are eminently demanded to limit the severity of clinical health problems associated with influenza A virus infections. An ideal alternative drug should be low cost generic medications, easily accessible in pandemics events. This type of drug should aim at the host's immune response to alleviate the effects of influenza and also exhibit ameliorated efficacy and safety by targeting required cellular proteins for influenza virus replication [39-41]. One of the advantages of this approach is avoiding development of drug resistance. Such drugs target common pathways used by host and influenza virus $[42,43]$. Since influenza A viruses widely use the host cell machinery to support the replication and transportation of their own viral components [20], targeting the host's response for exclusively attacking the virus could be advantageous. However, this strategy requires a better enlightenment of the intracellular pathways by which the influenza virus replicates [42].
Therefore, anti-inflammatory and immunomodulatory agents can be effective alternative therapeutics to vaccines and conventional antiviral drugs [16]. For the first time, the idea of statin usage to reduce pandemic mortality was suggested by Fedson [16] and, recently, these immunomodulatory agents have attracted much attention [44]. Statins can block downstream molecules that are key factors in virus infectivity [4]. These compounds are promising alternatives for influenza treatments by limiting inflammation, preventing cellular destruction [45]. Influenza pathogenesis and immune response of the infected cells with more focus on the statins mechanisms of action are shown in Figure 1.

\section{In Vitro Study}

Statins represent one of the most widely prescribed drugs in the world; therefore, identifying their capacity to reduce influenza virus mortality and morbidity during a pandemic is a matter of public health importance. However, in vitro studies regarding the effects of statins against influenza virus are limited.

Haidari and collaborators tested statin's inhibitory effects on the Rho/Rho kinase pathway, which led to the inhibition of influenza virus proliferation, with the use of atorvastatin and rosuvastatin against $\mathrm{H} 3 \mathrm{~N} 2$ and $\mathrm{H} 1 \mathrm{~N} 1$ strains in MadinDarby canine kidney (MDCK) cells [40]. They showed the involvement of Rho/Rho kinase pathway in virus proliferation, through which statins exhibit anti-influenza effects by downregulating the Rho/Rho kinase pathway [40]. The anti-inflammatory effects of statins against H1N1 infection in Crandell feline kidney (CrFK) cells have also been recently investigated [12]. It was found that atorvastatin, simvastatin and pravastatin were equally effective in reducing the expression levels of proinflammatory cytokines such as TNF- $\alpha$ and IL-6. In addition, atorvastatin-, simvastatin-, and pravastatintreated H1N1 infected cells showed significant decrement in the expression of proinflammatory cytokine proteins, compared to the virus infected cells alone [12]. Therefore, statins might be considered as a competent supplementary to conventional therapeutics in controlling the cytokines' overproduction.

The study by Lee et al. [14] demonstrated the attenuation of viral dsRNA-induced AKT phosphorylation, STAT3 activation, and the subsequent production of RANTES using simvastatin treatment in primary normal human bronchial epithelial cells (NHBE) and a human type II pneumocyte cell line A549.

Recently, it was shown that atorvastatin is as effective as amantadine and oseltamivir in reducing viral titer and augmenting cell viability following infection with the H1N1 strain in MDCK cells [46]. Another study demonstrated that H1N1 infection activates RhoA protein prenylation and induces actin cytoskeleton remodeling. Hence, simvastatin may reduce the replication of $\mathrm{H} 1 \mathrm{~N} 1$ by the possible blocking of RhoA membrane localization and inducing actin filaments condensation. Consequently, simvastatin can affect the upregulated RhoA pathway induced by H1N1 [47]. Simvastatin also showed analogous effects on the expression of Rab 


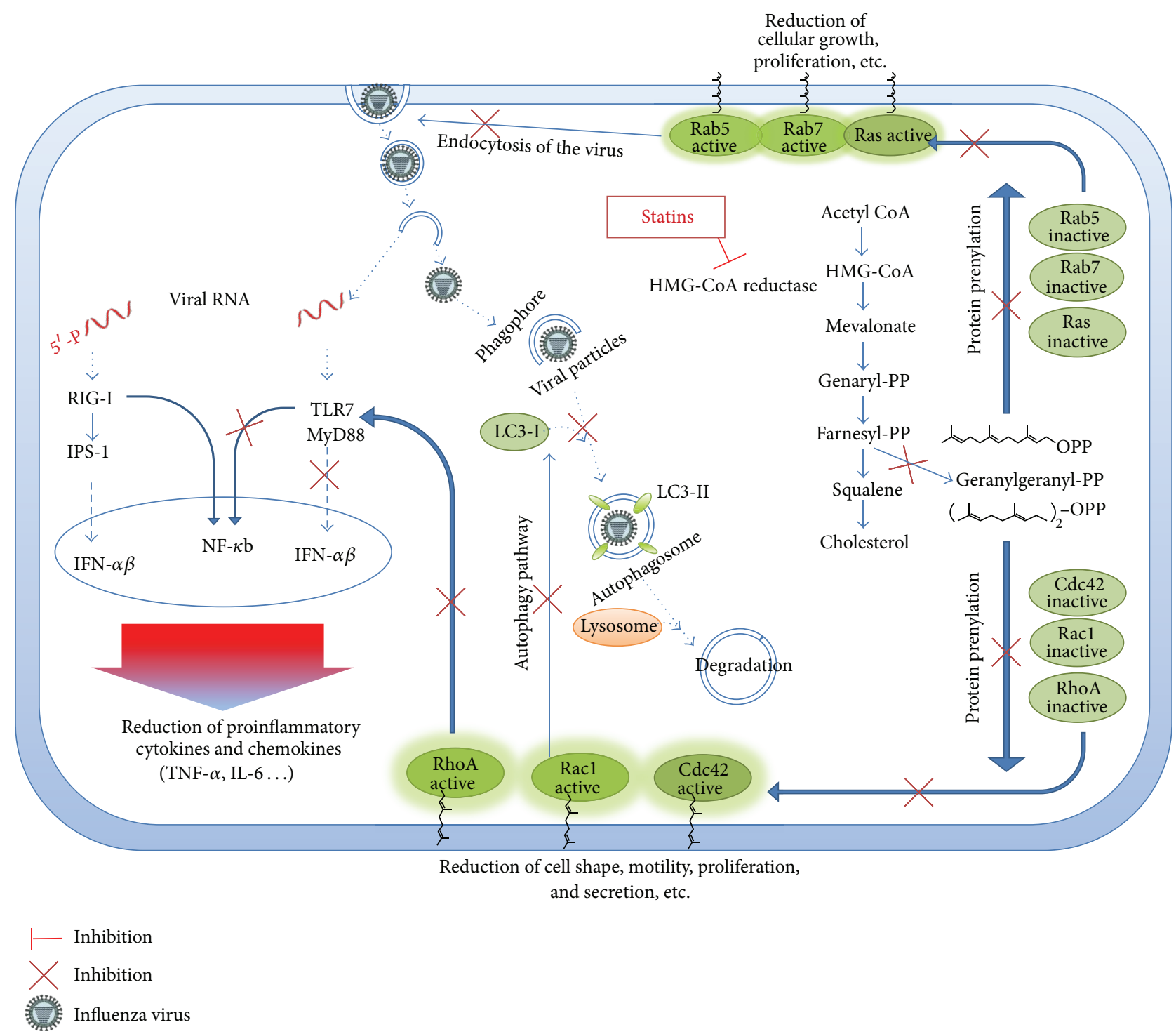

FIgURE 1: Possible mechanisms of statin action against influenza A virus pathogenesis in cellular and molecular structures.

proteins during endocytosis. In that study, LC3-II protein localization, an important marker involved in the autophagy process, was affected by simvastatin which contribute to retardation in the maturation process of autophagosomes [47].

All in all, in vitro studies showed the possible promising functions of atorvastatin, simvastatin, and pravastatin as the representatives of the statin family, on several cellular pathways to block the virus-host interaction system, which can act as an effective compound opposed to H1N1 infection.

\section{Animal Study}

Selected animal studies have further recommended a protective role for statin drugs against acute lung injury; however, results have been confounding. Gower and Graham in 2001 tested lovastatin against the respiratory syncytial virus and proposed lovastatin as an antiviral agent that controls the
RhoA membrane localization and affects virus replication [48]. Jacobson et al. [49] confirmed significant protection by simvastatin on LPS-induced lung vascular inflammation and implicated a potential role for statins in the management of acute lung injury; however, Ferraro et al. [50] adverted to nonsignificant effect of simvastatin on inflammatory biomarkers in lung injuries. Nevertheless, Haidari et al. [40], who examined atorvastatin on C57BL/6 mice infected with $\mathrm{H} 3 \mathrm{~N} 2$ and H1N1, showed reduced lung virus titers and mortality rates. In addition, several subsequent studies have shown partial benefits of statin in the recovery from influenza virus infection. However, these studies have not generally engaged contemporary, wild-type viruses and have not widely examined statin drugs along with commercially available antiviral treatments [51-53].

The domination of cytokines' overexpression during influenza virus infection is a debatable topic. Two separate studies on experimental infections using knockout mice 
showed poor efficacy of treating influenza infections with immunomodulatory agents $[54,55]$. They deduced that overproduction of cytokines might not be the cause of death during the H5N1 disease. Early inhibition of viral replication might be more promising in promoting survival of influenza virus infection than inhibition of the cytokine response. However, these two studies came from experiments conducted on small numbers of knockout mice, which does not provide sufficient basis for a conclusion.

Liu et al. [56] conducted a study in a murine model to evaluate the effectiveness and safety of a novel statin/caffeine mixture opposed to $\mathrm{H} 5 \mathrm{~N} 1, \mathrm{H} 3 \mathrm{~N} 2$, and $\mathrm{H} 1 \mathrm{~N} 1$ influenza virus infections. Caffeine is a constituent of the methylxanthine family [57], which has shown potential therapeutic effectiveness [58]. Caffeine modulates both innate and adaptive immune responses and prolongs the analgesic activities of painkillers, along with the effects of many other drugs [59]. In this study conducted by Liu et al. administration of $50 \mu \mathrm{g}$ statin $/ 200 \mu \mathrm{g}$ caffeine mixture was as effective as oseltamivir and ribavirin in inhibiting virus replication and improving lung damage.

Recently, two studies that have evaluated the efficacy of statin treatment in influenza virus-infected mice showed that treatments had no effect on survival. Their experiments flaws could be related to choosing improper lethal dose of the viruses in the short treatment duration $[34,52]$.

In a study, Belser et al. [60] inoculated the BALB/c mice with $\mathrm{H} 5 \mathrm{~N} 1$ or $\mathrm{pH} 1 \mathrm{~N} 1$ after an oral administration of simvastatin and oseltamivir to determine the susceptibility of different influenza viruses to statin treatment. The blood has been analyzed for circulating lymphocytes, virus titration, and proinflammatory cytokines and chemokines. No prominent antiviral activity of simvastatin alone or in combination therapy has been found in comparison with solely oseltamivir therapy in mice. However, reduced hypercytokinemia following $\mathrm{H} 5 \mathrm{~N} 1$ but not $\mathrm{pH} 1 \mathrm{~N} 1$ infections in mice, after simvastatin administration, reinforces the notion of dependence of this treatment on virus strain. This study supports further research on using statin to ameliorate severe influenza diseases. Glück and colleagues also showed failure of simvastatin to protect mice against influenza virus infection [61]. They administered simvastatin in two different ways orally and/or intraperitoneally once daily, starting 3 days before virus infection until 14 days post infection. However, in any dosage or route of administration simvastatin did not enhance the survival rate.

Meanwhile, Lee et al. [14] developed a dsRNA-induced viral pneumonia mouse model and delivered statins by intranasal route, which allowed direct contact with the respiratory epithelium. They demonstrated that statins decreased STAT3 and RANTES expression in airway epithelia as compared to controls. Statins also attenuated the proinflammatory cytokine response and decreased neutrophil influx. Their findings were in accord with earlier published studies [62]. As shown in animal studies, statin treatments may be of particular benefit in severe cases of influenza virus infections by reducing influenza virus-induced pulmonary inflammation. However, further studies are required to elucidate the proper usage of this treatment approach as opposed to different virus strains.

\section{Human Study}

Despite contradictory reports, several retrospective observational studies have identified a connection between statin use and reduction of influenza virus morbidity in humans; however, considerable variability in timing and duration of drug administration among participants may restrict the results of these studies $[25,26,32,63]$.

Two epidemiological studies evaluated the statin/influenza hypothesis. One was conducted in the Netherlands, using a general administrative database. The other used the United Kingdom's General Research Database. They found that patients who were under statin treatments for the prevention of cardiovascular diseases were protected against influenza-associated symptoms, with reductions in influenza-related pneumonia, acute myocardial infarction, and stroke [64]. Later, in another major study, Frost et al. [25] published a study using a health maintenance organization, encountering data from several moderate-sized health maintenance organizations in New Mexico. They found $40 \%$ lower mortality rate of pneumonia and influenza in the recipients of moderate doses of statins ( $\geq 4 \mathrm{mg} /$ day) compared to nonrecipients. Few years later, another study in Mexico showed higher survival rate in cases treated with statin (pravastatin $40 \mathrm{mg} /$ day) which have been reported in a small number of influenza patients admitted to an intensive care unit [28]. However, simultaneously a cohort study by Viasus et al. [29] on pneumonia patients in Spain did not show any improvement by anti-inflammatory therapy. Up to this point, two randomized controlled trial (RCT) found beneficial effects of oral administration of statin in reducing the frequency of viral pneumonia [30, 65]. However, recently, another RCT on treating pneumonia patients with simvastatin did not support the statin administration for viral pneumonia [33].

Vandermeer et al. [32] evaluated the relationship between statin administration and mortality in hospitalized patients. For the first time, he used the data from CDC Emerging Infections Program (EIP) of influenza hospitalization surveillance that amassed information on hospitalized patients with laboratory-confirmed influenza. It was shown that statins decrease death among certain cases. Other published studies, evaluating the role of statins in reducing mortality from sepsis and community-acquired pneumonia $[66,67]$, suggest that their findings are conceivable.

Not all epidemiological studies are in favor of statin beneficiary effects on influenza-related illnesses. The study of Fleming et al. [27] did not find any benefit to statin use on the incidence of acute respiratory infections [27]. Their study included influenza-like illnesses such as acute bronchitis, pneumonia, and upper respiratory infections; however, they did not include earlier and severer conditions of influenza infections. In an observational study, Kwong et al. [26] evaluated the association between statins and pneumonia and influenza hospitalizations in elderly patients using a 
TABLE 1: Human studies on the efficacy of using statins in acute respiratory patients.

\begin{tabular}{|c|c|c|}
\hline Reference & Summary of the study & Conclusions \\
\hline Frost et al., 2007 [25] & $\begin{array}{l}\text { Investigating the relation of mortality risk and } \\
\text { survival time with statin therapy in influenza and } \\
\text { COPD patients. }\end{array}$ & $\begin{array}{l}\text { Moderate dosage of statin treatment }(\leq 4 \mathrm{mg} / \mathrm{d}) \\
\text { significantly reduced the mortality rate and survival } \\
\text { time }(P<0.05) \text {. }\end{array}$ \\
\hline Kwong et al., 2009 [26] & $\begin{array}{l}\text { A cohort study of association between statins and } \\
\text { pneumonia and influenza hospitalizations in } \\
\text { elderly patients using data from ten influenza } \\
\text { seasons in Ontario, Canada. }\end{array}$ & $\begin{array}{l}\text { No considerable reduction in morbidity and } \\
\text { mortality of influenza has been observed in } \\
\text { statin-treated patients. }\end{array}$ \\
\hline Fleming et al., 2010 [27] & $\begin{array}{l}\text { Prospective study of the effects of statin on acute } \\
\text { respiratory infections in primary care. }\end{array}$ & $\begin{array}{l}\text { No beneficiary effects of statins on respiratory } \\
\text { diseases have been observed. However, there was a } \\
\text { kind of synergistic relation between statins and } \\
\text { influenza vaccines. }\end{array}$ \\
\hline Carrillo-Esper et al., 2011 [28] & $\begin{array}{l}\text { Retrospective study of } 26 \text { patients with severe } \\
\text { influenza in H1N1 influenza virus outbreak in } \\
2009 \text {. }\end{array}$ & $\begin{array}{l}\text { Combination treatments with methyl prednisolone, } \\
\text { activated protein } C \text {, and statins had significantly } \\
\text { increased the survival }(P<0.05) \text {. }\end{array}$ \\
\hline Viasus et al., 2011 [29] & $\begin{array}{l}\text { Cohort study of patients in pandemic influenza A } \\
\text { (H1N1), 2009, complicated by pneumonia. }\end{array}$ & $\begin{array}{l}\text { None of the therapies (corticosteroids, macrolides, } \\
\text { and statins) were found effective to reduce the risk of } \\
\text { severe disease. }\end{array}$ \\
\hline Makris et al., 2011 [30] & $\begin{array}{l}\text { A randomized controlled trial of ventilator } \\
\text { associated pneumonia with oral pravastatin } \\
\text { sodium. }\end{array}$ & $\begin{array}{l}\text { This study evidenced that pravastatin may ameliorate } \\
\text { the frequency of viral pneumonia. }\end{array}$ \\
\hline Yende et al., 2011 [31] & $\begin{array}{l}\text { Association of statin usage on clinical outcome } \\
\text { and circulating biomarkers of } \\
\text { community-acquired pneumonia patients. }\end{array}$ & $\begin{array}{l}\text { Only a modest change in circulating biomarkers has } \\
\text { been observed in statin-treated patients. }\end{array}$ \\
\hline Vandermeer et al., 2012 [32] & $\begin{array}{l}\text { Investigating the relation of statin therapy with } \\
\text { influenza related death in laboratory confirmed } \\
\text { patients of } 59 \text { countries in } 10 \text { states. }\end{array}$ & $\begin{array}{l}\text { Statins may have beneficiary effects on reducing } \\
\text { mortality in hospitalized influenza patients. }\end{array}$ \\
\hline Papazian et al., 2013 [33] & $\begin{array}{l}\text { A randomized controlled trial of ventilator } \\
\text { associated pneumonia with simvastatin. }\end{array}$ & $\begin{array}{l}\text { The result of this study does not support positive } \\
\text { effects of simvastatin against ventilator associated } \\
\text { pneumonia patients. }\end{array}$ \\
\hline Kruger et al., 2013 [34] & $\begin{array}{l}\text { A randomized controlled trial of the effects of } \\
\text { atorvastatin on critically ill sepsis patients. }\end{array}$ & $\begin{array}{l}\text { This cohort study showed that continuation of } \\
\text { atorvastatin is associated with survival improvement. }\end{array}$ \\
\hline
\end{tabular}

cohort study data from ten influenza seasons in Ontario, Canada. They identified trivial protective effects of statins averse to influenza mortality. They suggested that statins do not considerably reduce the morbidity and mortality of influenza. Some studies even showed the recurrence of the symptoms after discontinuing statin treatment $[31,34]$.

Several limitations may affect the results of this study. Firstly, in an observational study the effects of unmeasured confounders cannot be eliminated. Secondly, their outcomes were nonspecific and may be because of various causes other than influenza. Thirdly, they did not have any information on medications used while patients were being hospitalized. And, finally, they used health administrative data to assess covariates with dubious accuracy of diagnostic codes. Conversely, some observational studies have suggested a potential beneficiary role for statins in the treatment of sepsis and community-acquired pneumonia [66,67]. A summary of the human studies was shown in Table 1.

It is necessary that people who have documented medical treatments in large administrative databases should undertake a comprehensive approach on the effects of statins in both retrospective cohort and case-control studies. Albeit, it is still ambiguous if these medications are truly beneficial
[68]; the epidemiological findings can be used to generate hypotheses for a wide range of laboratory and clinical studies. Based on all current information, statins may be promising agents in preventing severe disease outcomes, such as death. However, these agents may not play a dominant role in reducing infections or minor illnesses. Thus, statin's prescription should be done cautiously, with regards to the background of the patient's disease. Moreover, to improve outcomes, statin dosage, duration of treatment, and also conjunction therapy with other antivirals should be respected as well [69].

Hence, scientists should thoroughly study statins to elucidate the potential of these agents as one of the alternative drugs in dominating outbreaks of influenza A virus infections in future.

\section{Conclusion}

Influenza-related illnesses are acute diseases that affect most of the human population, with various outcomes ranging from impaired quality of life to fatal infections. Despite contradictory results from various studies, statins are inexpensive and easily available medications in developing countries. They have the potential to be used as prophylactic medicine 
or therapy against influenza disease. Surely, they will contribute to the protection against inflammation-associated diseases, by controlling the immune system's cytokine overexpression and modulating the intense inflammatory response.

Therefore, more comprehensive epidemiological, functional, and molecular research on the interactions between statins and influenza virus and host immune responses needs to be carried out. This will lead to the development of more potent statins based on better profiles of bioavailability, which will help open new promising therapies for looming and imminent outbreaks of influenza. Lastly, comprehensive clinical studies should verify the benefits of statins for the treatment of influenza-related illnesses.

\section{Abbreviations}

$\begin{array}{ll}\text { CDC: } & \text { Center for Disease Control and Prevention } \\ \text { CrFK: } & \text { Crandell feline kidney } \\ \text { EIP: } & \text { Emerging Infections Program } \\ \text { FPP: } & \text { Farnesyl pyrophosphate } \\ \text { GGPP: } & \text { Geranylgeranyl pyrophosphate } \\ \text { HMG-CoA: } & \text { Hydroxyl methylglutaryl-coenzyme A } \\ \text { MDCK: } & \text { Madin-Darby Canine Kidney } \\ \text { RCT: } & \text { Randomized Controlled Trial. }\end{array}$

\section{Conflict of Interests}

The authors declare that there is no conflict of interests regarding the publication of this paper.

\section{Authors' Contribution}

Parvaneh Mehrbod designed methods and experiments and collected data. Parvaneh Mehrbod carried out the laboratory experiments and drafted the paper. All authors revised the paper critically for important intellectual content. All authors have seen and approved the paper.

\section{Acknowledgments}

This study was funded by Grant no. 01-02-04-009 BTK/ER/38 from the Ministry of Science, Technology and Innovation, Government of Malaysia.

\section{References}

[1] E. J. Armstrong and P. K. Safo, "Pharmacology of cholesterol and lipoprotein metabolism," in Principles of Pharmacology: The Pathophysiologic Basis of Drug Therapy, pp. 369-389, Lippincott Williams \& Wilkins, Baltimore, Md, USA, 2005.

[2] A. Endo, "The discovery and development of HMG-CoA reductase inhibitors," Journal of Lipid Research, vol. 33, no. 11, pp. 1569-1582, 1992.

[3] I. Darwish, S. Mubareka, and W. C. Liles, "Immunomodulatory therapy for severe influenza," Expert Review of Anti-Infective Therapy, vol. 9, no. 7, pp. 807-822, 2011.

[4] X. Sun and G. R. Whittaker, "Role for influenza virus envelope cholesterol in virus entry and infection," Journal of Virology, vol. 77, no. 23, pp. 12543-12551, 2003.
[5] J. L. Goldstein and M. S. Brown, "Regulation of the mevalonate pathway," Nature, vol. 343, no. 6257, pp. 425-430, 1990.

[6] L. M. Blanco-Colio, J. Tuñón, J. L. Martín-Ventura, and J. Egido, "Anti-inflammatory and immunomodulatory effects of statins," Kidney International, vol. 63, no. 1, pp. 12-23, 2003.

[7] U. Laufs, M. Endres, F. Custodis et al., "Suppression of endothelial nitric oxide production after withdrawal of statin treatment is mediated by negative feedback regulation of rho GTPase gene transcription," Circulation, vol. 102, no. 25, pp. 3104-3110, 2000.

[8] P. J. Casey, P. A. Solski, C. J. Der, and J. E. Buss, "p21ras is modified by a farnesyl isoprenoid," Proceedings of the National Academy of Sciences of the United States of America, vol. 86, no. 21, pp. 8323-8327, 1989.

[9] J. K. Liao and U. Laufs, "Pleiotropic effects of statins," Annual Review of Pharmacology and Toxicology, vol. 45, pp. 89-118, 2005.

[10] M. Terblanche, Y. Almog, R. S. Rosenson, T. S. Smith, and D. G. Hackam, "Statins and sepsis: multiple modifications at multiple levels," The Lancet Infectious Diseases, vol. 7, no. 5, pp. 358-368, 2007.

[11] S. E. Alexeeff, A. A. Litonjua, D. Sparrow, P. S. Vokonas, and J. Schwartz, "Statin use reduces decline in lung function: VA normative aging study," American Journal of Respiratory and Critical Care Medicine, vol. 176, no. 8, pp. 742-747, 2007.

[12] P. Mehrbod, M. El Zowalaty, A. R. Omar, M. Hair-Bejo, and A. Ideris, "Statins reduce the expression of proinflammatory cytokines in influenza A virus infected CrFK cells," Acta Virologica, vol. 56, no. 4, pp. 353-355, 2012.

[13] K. L. Watts, E. M. Sampson, G. S. Schultz, and M. A. Spiteri, "Simvastatin inhibits growth factor expression and modulates profibrogenic markers in lung fibroblasts," American Journal of Respiratory Cell and Molecular Biology, vol. 32, no. 4, pp. 290300, 2005.

[14] C. S. Lee, E. H. Yi, J.-K. Lee et al., "Simvastatin suppresses RANTES-mediated neutrophilia in polyinosinic-polycytidylic acid-induced pneumonia," European Respiratory Journal, vol. 41, no. 5, pp. 1147-1156, 2013.

[15] M. Blanc, W. Y. Hsieh, K. A. Robertson et al., "Host defense against viral infection involves interferon mediated downregulation of sterol biosynthesis," PLoS Biology, vol. 9, no. 3, Article ID e1000598, 2011.

[16] D. S. Fedson, "Pandemic influenza: a potential role for statins in treatment and prophylaxis," Clinical Infectious Diseases, vol. 43, no. 2, pp. 199-205, 2006.

[17] M. Terblanche, T. S. Smith, and N. K. J. Adhikari, "Statins, bugs and prophylaxis: intriguing possibilities," Critical Care, vol. 10, no. 5 , article $168,2006$.

[18] E. R. Campagnolo, J. T. Rankin, S. A. Daverio et al., "Fatal pandemic (H1N1) 2009 influenza A virus infection in a pennsylvania domestic cat," Zoonoses and Public Health, vol. 58, no. 7, pp. 500-507, 2011.

[19] R. J. Garten, C. T. Davis, C. A. Russell et al., "Antigenic and genetic characteristics of swine-origin $2009 \mathrm{~A}(\mathrm{H} 1 \mathrm{N1})$ influenza viruses circulating in humans," Science, vol. 325, no. 5937, pp. 197-201, 2009.

[20] M. D. de Jong, C. P. Simmons, T. T. Thanh et al., "Fatal outcome of human influenza A (H5N1) is associated with high viral load and hypercytokinemia," Nature Medicine, vol. 12, no. 10, pp. 1203-1207, 2006.

[21] G. Lippi, M. Franchini, and E. J. Favaloro, "Influenza and cardiovascular disease: does swine-origin, 2009 H1N1 flu virus 
represent a risk factor, an acute trigger, or both?" Seminars in Thrombosis and Hemostasis, vol. 36, no. 1, pp. 49-58, 2010.

[22] C. Y. Cheung, L. L. M. Poon, A. S. Lau et al., "Induction of proinflammatory cytokines in human macrophages by influenza A (H5N1) viruses: a mechanism for the unusual severity of human disease?" The Lancet, vol. 360, no. 9348, pp. 1831-1837, 2002.

[23] A. S. Lipatov, S. Andreansky, R. J. Webby et al., "Pathogenesis of Hong Kong H5N1 influenza virus NS gene reassortants in mice: the role of cytokines and B- and T-cell responses," Journal of General Virology, vol. 86, no. 4, pp. 1121-1130, 2005.

[24] M. T. Osterholm, "Preparing for the next pandemic," New England Journal of Medicine, vol. 352, no. 18, pp. 1839-1842, 2005.

[25] F. J. Frost, H. Petersen, K. Tollestrup, and B. Skipper, "Influenza and COPD mortality protection as pleiotropic, dose-dependent effects of statins," Chest, vol. 131, no. 4, pp. 1006-1012, 2007.

[26] J. C. Kwong, P. Li, and D. A. Redelmeier, "Influenza morbidity and mortality in elderly patients receiving statins: a cohort study," PLoS ONE, vol. 4, no. 11, Article ID e0008087, 2009.

[27] D. M. Fleming, N. Q. Verlander, A. J. Elliot et al., "An assessment of the effect of statin use on the incidence of acute respiratory infections in England during winters 1998-1999 to 2005-2006," Epidemiology and Infection, vol. 138, pp. 1-8, 2010.

[28] R. Carrillo-Esper, J. Ojino Sosa-García, and E. Arch-Tirado, "Experience in the management of the severe form of human influenza A H1N1 pneumonia in an intensive care unit," Cirugia y Cirujanos, vol. 79, no. 5, pp. 409-416, 2011.

[29] D. Viasus, J. Ramón Paño-Pardo, E. Cordero et al., "Effect of immunomodulatory therapies in patients with pandemic influenza A (H1N1) 2009 complicated by pneumonia," Journal of Infection, vol. 62, no. 3, pp. 193-199, 2011.

[30] D. Makris, E. Manoulakas, A. Komnos et al., "Effect of pravastatin on the frequency of ventilator-associated pneumonia and on intensive care unit mortality: open-label, randomized study," Critical Care Medicine, vol. 39, no. 11, pp. 2440-2446, 2011.

[31] S. Yende, E. B. Milbrandt, J. A. Kellum et al., "Understanding the potential role of statins in pneumonia and sepsis," Critical Care Medicine, vol. 39, no. 8, pp. 1871-1878, 2011.

[32] M. L. Vandermeer, A. R. Thomas, L. Kamimoto et al., "Association between use of statins and mortality among patients hospitalized with laboratory-confirmed influenza virus infections: a multistate study," Journal of Infectious Diseases, vol. 205, no. 1, pp. 13-19, 2012.

[33] L. Papazian, A. Roch, P.-E. Charles et al., "Effect of statin therapy on mortality in patients with ventilator-associated pneumonia: a randomized clinical trial," Journal of the American Medical Association, vol. 310, no. 16, pp. 1692-1700, 2013.

[34] P. Kruger, M. Bailey, R. Bellomo et al., "A multicenter randomized trial of atorvastatin therapy in intensive care patients with severe sepsis," American Journal of Respiratory and Critical Care Medicine, vol. 187, no. 7, pp. 743-750, 2013.

[35] I. M. Lagoja and E. de Clercq, "Anti-influenza virus agents: synthesis and mode of action," Medicinal Research Reviews, vol. 28, no. 1, pp. 1-38, 2008.

[36] A. Moscona, "Global transmission of oseltamivir-resistant influenza," New England Journal of Medicine, vol. 360, no. 10, pp. 953-956, 2009.

[37] M. Baz, Y. Abed, J. Papenburg, X. Bouhy, M. È. Hamelin, and G. Boivin, "Emergence of oseltamivir-resistant pandemic H1N1 virus during prophylaxis," The New England Journal of Medicine, vol. 361, no. 23, pp. 2296-2297, 2009.
[38] A. E. Fiore, D. K. Shay, K. Broder et al., "Prevention and control of influenza: recommendations of the advisory committee on immunization practices," Recommendations and Reports, vol. 57, no. 7, pp. 1-60, 2008.

[39] D. S. Fedson, "Confronting an influenza pandemic with inexpensive generic agents: can it be done?" The Lancet Infectious Diseases, vol. 8, no. 9, pp. 571-576, 2008.

[40] M. Haidari, A. Muzammil, S. W. Casscells, and M. Madjid, "Statins block influenza infection by down-regulating Rho/Rho kinase pathway," Circulation, vol. 116, pp. 116-117, 2007.

[41] S. Ludwig, "Disruption of virus-host cell interactions and cell signaling pathways as an anti-viral approach against influenza virus infections," Biological Chemistry, vol. 392, no. 10, pp. 837$847,2011$.

[42] M. Haidari, W. Zhang, L. Ganjehei, M. Ali, and Z. Chen, "Inhibition of MLC phosphorylation restricts replication of influenza virus-a mechanism of action for anti-influenza agents," PLoS ONE, vol. 6, no. 6, Article ID e21444, 2011.

[43] G. R. Whittaker, "Intracellular trafficking of influenza virus: clinical implications for molecular medicine," Expert Reviews in Molecular Medicine, vol. 3, pp. 1-13, 2001.

[44] D. S. Hui and N. Lee, "Adjunctive therapies and immunomodulating agents for severe influenza," Influenza and other Respiratory Viruses, vol. 7, no. 3, pp. 52-59, 2013.

[45] L. M. Alleva, R. C. Gualano, and I. A. Clark, "Current work and future possibilities for the management of severe influenza: Using immunomodulatory agents that target the host response," Future Virology, vol. 6, no. 7, pp. 843-854, 2011.

[46] P. Mehrbod, A. Ideris, A. R. Omar, and M. Hair-Bejo, "Evaluation of antiviral effect of atorvastatin on H1N1 infection in MDCK cells," African Journal of Microbiology Research, vol. 6, no. 27, pp. 5715-5719, 2012.

[47] P. Mehrbod, M. Hair-Bejo, T. A. Tengku Ibrahim et al., "Simvastatin modulates cellular components in influenza A virusinfected cells," International Journal of Molecular Medicine, vol. 34, no. 1, pp. 61-73, 2014.

[48] T. L. Gower and B. S. Graham, "Antiviral activity of lovastatin against respiratory syncytial virus in vivo and in vitro," Antimicrobial Agents and Chemotherapy, vol. 45, no. 4, pp. 1231-1237, 2001.

[49] J. R. Jacobson, J. W. Barnard, D. N. Grigoryev, S.-F. Ma, R. M. Tuder, and J. G. N. Garcia, "Simvastatin attenuates vascular leak and inflammation in murine inflammatory lung injury," American Journal of Physiology - Lung Cellular and Molecular Physiology, vol. 288, no. 6, pp. L1026-L1032, 2005.

[50] S. A. Ferraro, J. S. Yakisich, F. T. Gallo, and D. R. Tasat, "Simvastatin pretreatment prevents ambient particle-induced lung injury in mice," Inhalation Toxicology, vol. 23, no. 14, pp. 889-896, 2011.

[51] S.-C. An, L.-L. Xu, F.-D. Li, L.-L. Bao, C. Qin, and Z.-C. Gao, "Triple combinations of neuraminidase inhibitors, statins and fibrates benefit the survival of patients with lethal avian influenza pandemic," Medical Hypotheses, vol. 77, no. 6, pp. 1054-1057, 2011.

[52] Y. Kumaki, J. D. Morrey, and D. L. Barnard, "Effect of statin treatments on highly pathogenic avian influenza H5N1, seasonal and H1N1pdm09 virus infections in BALB/c mice," Future Virology, vol. 7, no. 8, pp. 801-818, 2012.

[53] K. A. Radigan, D. Urich, A. V. Misharin et al., "The effect of rosuvastatin in a murine model of influenza a infection," PLoS ONE, vol. 7, no. 4, Article ID e35788, 2012. 
[54] R. Salomon, E. Hoffmann, and R. G. Webster, "Inhibition of the cytokine response does not protect against lethal H5N1 influenza infection," Proceedings of the National Academy of Sciences of the United States of America, vol. 104, no. 30, pp. 12479-12481, 2007.

[55] K. J. Szretter, S. Gangappa, X. Lu et al., "Role of host cytokine responses in the pathogenesis of avian $\mathrm{H} 5 \mathrm{~N} 1$ influenza viruses in mice," Journal of Virology, vol. 81, no. 6, pp. 2736-2744, 2007.

[56] Z. Liu, Z. Guo, G. Wang et al., "Evaluation of the efficacy and safety of a statin/caffeine combination against H5N1, H3N2 and H1N1 virus infection in BALB/c mice," European Journal of Pharmaceutical Sciences, vol. 38, no. 3, pp. 215-223, 2009.

[57] L. A. Horrigan, J. P. Kelly, and T. J. Connor, "Immunomodulatory effects of caffeine: friend or foe?" Pharmacology and Therapeutics, vol. 111, no. 3, pp. 877-892, 2006.

[58] N. L. Benowitz, "Clinical pharmacology of caffeine," Annual Review of Medicine, vol. 41, no. 1, pp. 277-288, 1990.

[59] B. Renner, G. Clarke, T. Grattan et al., "Caffeine accelerates absorption and enhances the analgesic effect of acetaminophen," Journal of Clinical Pharmacology, vol. 47, no. 6, pp. 715-726, 2007.

[60] J. A. Belser, K. J. Szretter, J. M. Katz, and T. M. Tumpey, "Simvastatin and oseltamivir combination therapy does not improve the effectiveness of oseltamivir alone following highly pathogenic avian H5N1 influenza virus infection in mice," Virology, vol. 439, no. 1, pp. 42-46, 2013.

[61] B. Glück, M. Schmidtke, M. Walther, A. Meerbach, and P. Wutzler, "Simvastatin treatment showed no prophylactic effect in influenza virus-infected mice," Journal of Medical Virology, vol. 85, no. 11, pp. 1978-1982, 2013.

[62] M. B. Fessler, S. K. Young, S. Jeyaseelan et al., "A role for hydroxy-methylglutaryl coenzyme A reductase in pulmonary inflammation and host defense," American Journal of Respiratory and Critical Care Medicine, vol. 171, no. 6, pp. 606-615, 2005.

[63] S. J. Brett, P. Myles, W. S. Lim et al., "Pre-admission statin use and in-hospital severity of 2009 pandemic influenza A(H1N1) disease," PLoS ONE, vol. 6, no. 4, Article ID e18120, 2011.

[64] M. Enserink, "Old drugs losing effectiveness against flu; could statins fill gap?” Science, vol. 309, no. 5743, pp. 1976-1977, 2005.

[65] S. Janda, A. Young, J. M. FitzGerald, M. Etminan, and J. Swiston, "The effect of statins on mortality from severe infections and sepsis: a systematic review and meta-analysis," Journal of Critical Care, vol. 25, no. 4, pp. 656.e7-656.e22, 2010.

[66] M. E. Falagas, G. C. Makris, D. K. Matthaiou, and P. I. Rafailidis, "Statins for infection and sepsis: a systematic review of the clinical evidence," Journal of Antimicrobial Chemotherapy, vol. 61, no. 4, pp. 774-785, 2008.

[67] P. Kopterides and M. E. Falagas, "Statins for sepsis: a critical and updated review," Clinical Microbiology and Infection, vol. 15, no. 4, pp. 325-334, 2009.

[68] A. R. Boyd and E. M. Mortensen, "Are statins beneficial for viral pneumonia?" European Respiratory Journal, vol. 41, no. 5, pp. 1010-1011, 2013.

[69] F. G. Hayden, "Newer influenza antivirals, biotherapeutics and combinations," Influenza and other Respiratory Viruses, vol. 7, supplement 1, pp. 63-75, 2013. 

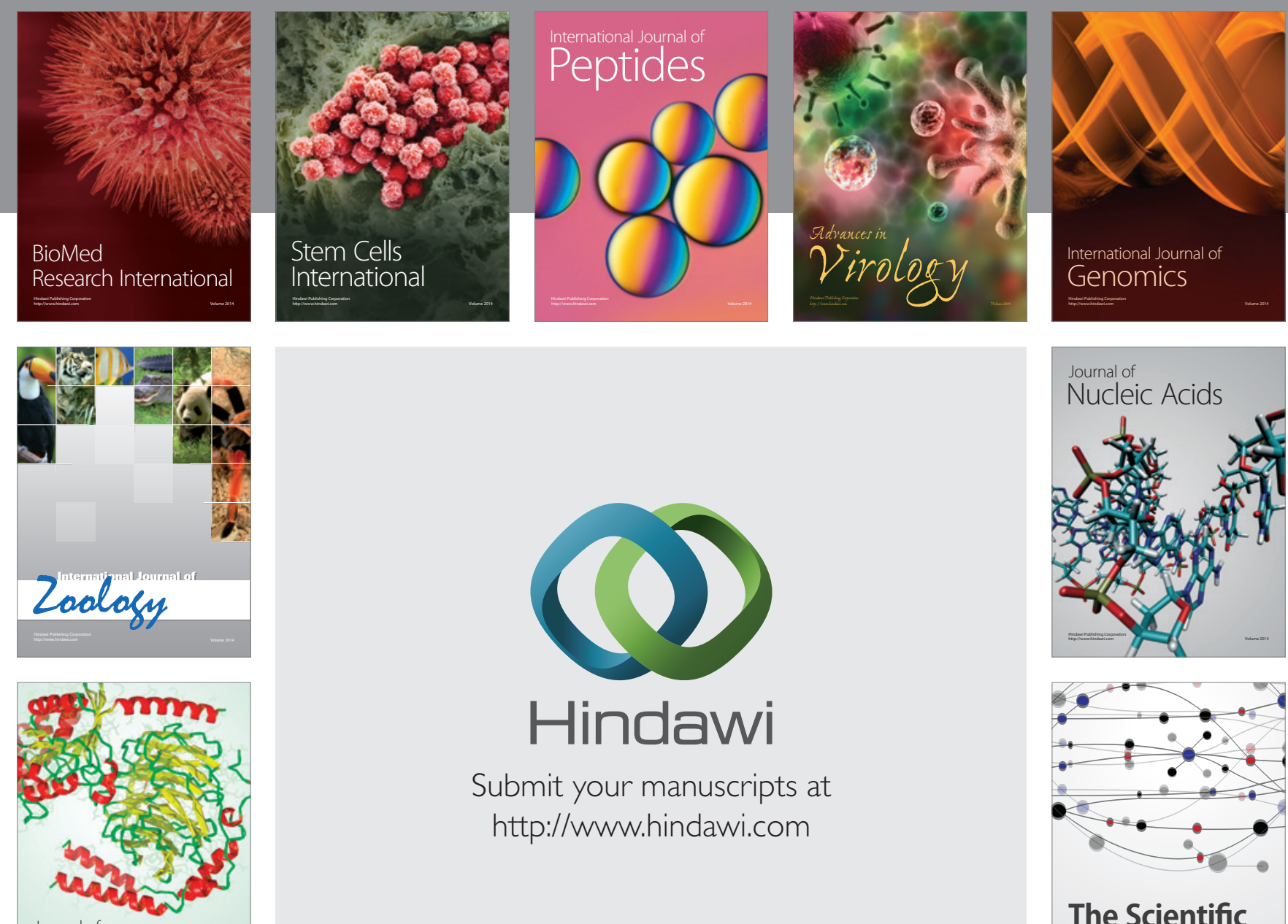

Submit your manuscripts at

http://www.hindawi.com

Journal of
Signal Transduction
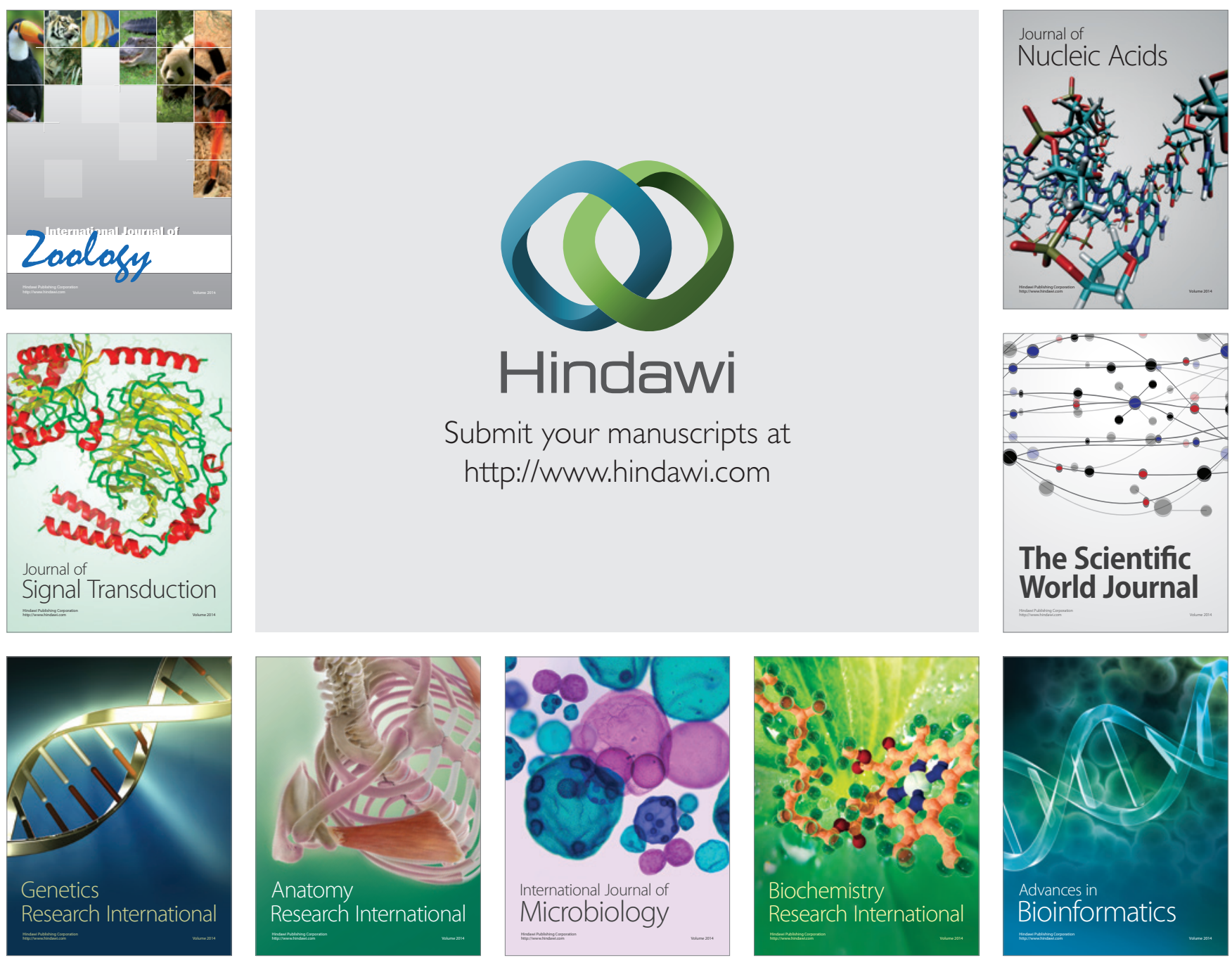

The Scientific World Journal
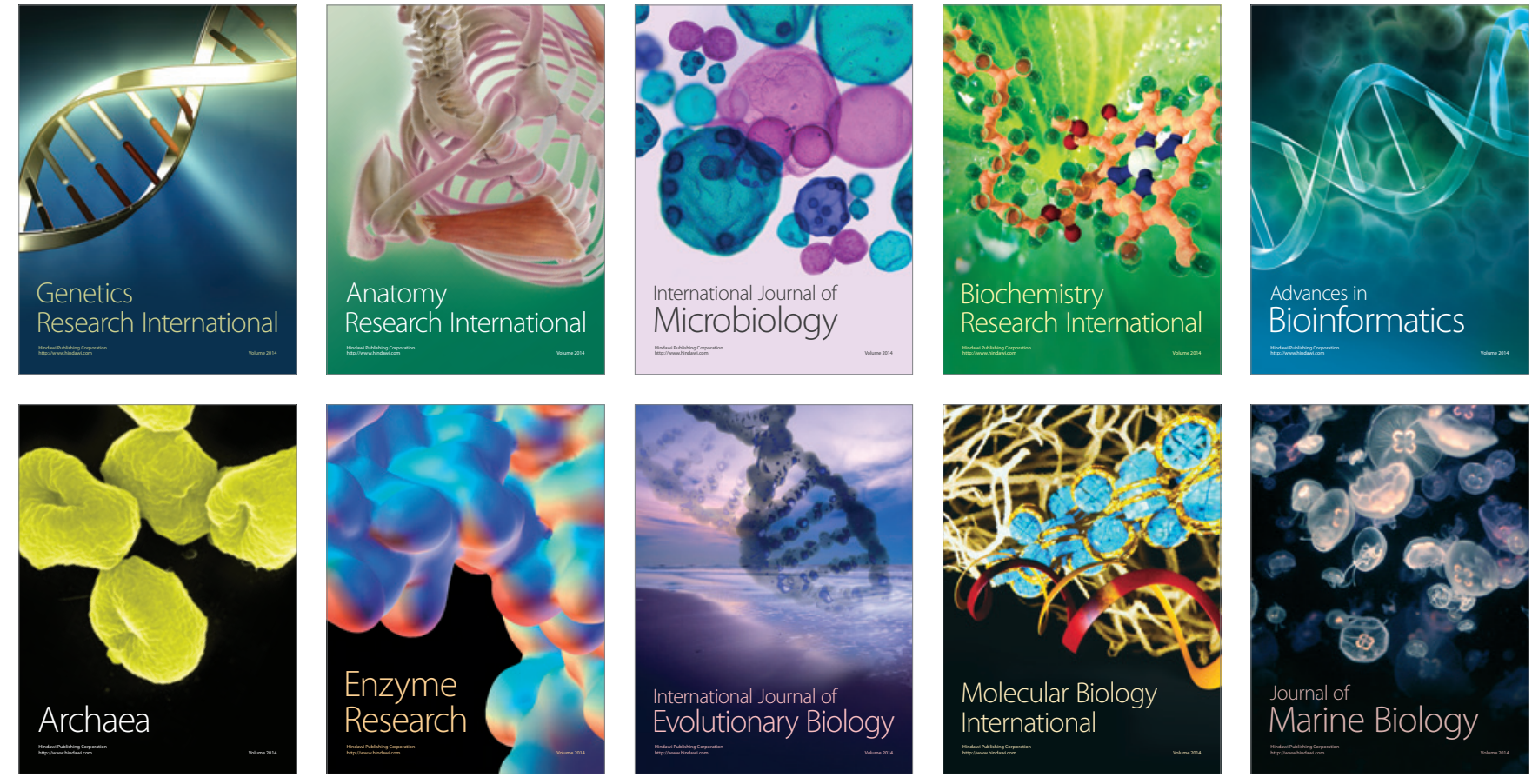